\title{
MORBIDLY ADHERENT PLACENTA -A BURDEN ON TERTIARY CARE CENTRE.
}

\footnotetext{
1. FCPS

Senior Registrar Obstetrics \& Gynaecology

Lahore General Hospital/PGMI/ Amer-ud-din Medical College.

2. MBBS, MCPS

Senior Registrar Obstetrics \&

Gynaecology

Lahore General Hospital/PGMI/

Amer-ud-din Medical College.

3. MBBS, FCPS

Senior Registrar Obstetrics \&

Gynaecology

Lahore General Hospital/PGMI/

Amer-ud-din Medical College.
}

Correspondence Address:

Dr. Zahra Safdar

193-C, Pak-Arab Hosing Society,

Ferozpur Road, Lahore.

zsafdar2@gmail.com

Article received on:

03/04/2019

Accepted for publication:

15/10/2019

\section{Zahra Safdar ${ }^{1}$, Sumera Zaib², Sumera Fatima ${ }^{3}$}

ABSTRACT... Objectives: To determine the burden of Morbidly Adherent Placenta on tertiary care centre in terms of prolonged hospital stay, multiple blood transfusions, Intensive care unit stay, involvement of surgical urological colleges. Study Design: Descriptive Case Series. Setting: Department of Obstetrics and Gynaecology, Unit I Lahore, General Hospital Lahore LGH. Period: 06 months (1 ${ }^{\text {st }}$ August 2017-28 ${ }^{\text {th }}$ February 2018). Material \& Methods: Total Obstetrical patients admitted in this period were 2754 total births 2567, lower segment caesarean 1184 patients, with Morbidly Adherent Placenta were 28. Date was analysed regarding maternal age, parity, previous surgeries and diagnosis prior to admission. The complications analysed were hospital stay >10 days, multiple transfusions >04 days, ICU admission $>72$ hours, requirement of surgical and urological colleges. Patients fulfilling inclusion and exclusion criteria were studied. Results: Morbidly Adherent Placenta results in patient's prolonged stay in hospital and ICU which results in high consumption of hospital resources. Conclusion: Morbidly Adherent Placenta is directly related with caesarean section rate. Every effort should be made to reduce the \%age of primary caesarean section so that incidence of Morbidly Adherent Placenta can be minimised.

Key words: $\quad$ Caesarean Section, Morbidly Adherent Placenta, Placenta Previa.

Article Citation: Safdar Z, Zaib S, Fatima S. Morbidly adherent placenta -A burden on tertiary care centre. Professional Med J 2020; 27(9):1795-1798.

DOI: 10.29309/TPMJ/2020.27.09.3466

\section{INTRODUCTION}

Maternal and fetal morbidity and mortality from placenta praevia are associated with high demands on health departments as it is common causes of antepartum bleeding and is associated with an increased need for blood transfusions and preterm delivery. ${ }^{1}$ There is continuous increase in the complications like placenta praevia with increase in the patient age combine with number of caesarean they experience..$^{2,3}$ Placenta previa (PP) is when placental tissue attaches inside the uterus but near or over the internal cervical. ${ }^{4}$ Ultrasound imaging classifies placenta previa to major and minor or partial praevia depend on its position in cervical. ${ }^{5-7}$ Morbidity Adherent Placenta is the abnormal invasion of trophoblastic tissues also known as abnormal invasion of placenta. Morbidly Adherent Placenta can be classified into1) Accreta-trophoblastic invasion upto $50 \%$ of the myometrium, and 2) Percreta the trophoblastic placenta perforates the uterine serosa and spreads to other pelvic organs. ${ }^{3,8,9}$

Morbidly Adherent Placenta is rising progressively and the rate which was one in 2500 pregnancies few years back is currently one in 500 pregnancies. The main cause is the complications experienced by women in previous delivery, according to one of UK based study UK Obstetric Surveillance System (UKOSS), the odds of having Morbidly Adherent Placenta increased in women having previous caesarean delivery, previous uterine surgery, an IVF pregnancy and placenta previa diagnosed antepartum. ${ }^{3}$

Previous caesarean section and anterior placenta should raise high index suspicion of Morbidly Adherent Placenta, especially if it is reported as low lying or praevia. Routine ultrasound can demonstrate the classical features of placental lacunae, thinning of the myometrial border and disruption of the posterior wall of the bladder. ${ }^{10}$ 
In Pakistan Morbidly Adherent Placenta is a big concern as there is social stress for a large family so there is increase in previous caesarean section, placenta praevia, placenta accrete and hysterectomy. ${ }^{11}$ According to one study the caesarean rate in Pakistan is $64.6 \%$ and it is increasing. ${ }^{12}$

Our aim of this study is to create awareness regarding rising incidence of Morbidly Adherent Placenta and its burdens on tertiary care centres so that early risk identification, early diagnosis, and referral can minimize the complications in patients who present in emergency with massive haemorrhage.

\section{MATERIAL \& METHODS}

The descriptive case series study was carried out within six months in the duration of August 01, 2017 to February 28, 2018. This study contained 28 cases which were admitted in Department of Obstetrics and Gynaecology, Unit I Lahore, General Hospital Lahore. Patients with the history of previous caesarean were prioritised in the study, all obstetrical patients admitted in the unit were included in the study and only those patients which were already operated upon outside hospital and were referred with complications of surgery carried out due to Morbidly Adherent Placenta were excluded.

The patient's details were collected from ICU and ward, complete history was documented with age menstrual cycle, estimated date of delivery, blood transfusion, bleeding history, complete oral and injected medication details with this pregnancy and previous pregnancies. The data collected were well informed to the subjects and with the consent added in this study.

In the duration of six months total number of 2754 Obstetrical patients were admitted with the birth rate of 2567 out of which 1184 were lower segment caesarean and with Morbidly Adherent Placenta were 28. The general examination of patient was done using routine urine examination, blood group, complete blood screening, and ultra-sonogram followed by the abdominal examination for lie of fetus, fundus height, fetal cardic sounds, expected fetal weight and utrine contractions during labouring. The complications analysed were stayed in hospital for more than 10 days with multiple transfusions in 04 days and admitted in ICU for 72 hours as per requirement of surgical and urological colleges.

All procedure performed in study involving human participants were in accordance with the ethical standards of the institution. Informed consent was obtained from all individual participants in the study.

\section{RESULTS}

This study include 28 subjects with Morbidity Adherent Placenta out of which 01 have previous 01 caesarean section, 07 have 02, 18 have 03 and 02 have 04 caesarean sections as indicated in Figure-1 with the maternal age between 21-36.

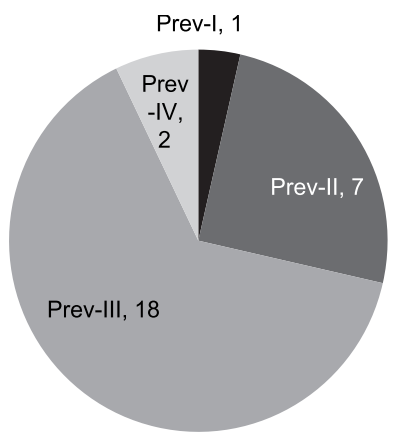

Figure-1. Parity association of Morbidly Adherent Placenta.

Hysterectomy was performed in $96.42 \%$ patients out of which $89.28 \%$ stayed in hospital for more than 10 days, $89.28 \%$ also requires more than 04 blood transfusions and $64.28 \%$ stayed in hospital for more than 72 hours.

The operative procedure also has some complications like out of control bleeding which requires the assistance of general surgery colleges as the case of $28.57 \%$ patients and $39.28 \%$ requires the assistance of urological colleagues because of uncontrolled bladder bleeding and stitching as indicated in Table-l. 


\begin{tabular}{|l|c|c|}
\hline \multicolumn{1}{|c|}{ Characteristics } & No & $\%$ age \\
\hline Morbidly Adherent Placenta & 28 & \\
\hline Hysterectomy & 27 & 96.42 \\
\hline Hospital stay> 10days & 25 & 89.28 \\
\hline Blood Transfusions >4 & 26 & 92.84 \\
\hline ICU stay >72hrs & 18 & 64.28 \\
\hline Requirement of surgical colleagues & 8 & 28.57 \\
\hline Requirement of Urological Colleagues & 11 & 39.28 \\
\hline Maternal Age & $21-36$ & 32.62 \\
Table-I. Morbidity associated with Morbidly Adherent \\
\hline \multirow{2}{|c}{ Placenta. }
\end{tabular}

\section{DISCUSSION}

Morbidly Adherent Placenta, a life threatening complication of pregnancy in approximately 1 in 1000 to 2000 pregnancies as reported but in our case study it is $1.09 \%$ which is quite high 1 in 91 patients results in risks to patients such as bleeding during pregnancy, excessive blood loss at times of delivery, premature delivery and need of hysterectomy which require complete attention of gynaecologist, surgical and urological team. Morbidly Adherent Placenta is the cause of excessive consumption of hospital resources because patients have to stay in hospital for more than 10 days and require blood transfusions too. ${ }^{11,13,14}$

It is also observed that the risk of Morbidly Adherent Placenta is high in older age group with higher gravidity and patients with previous caesarean delivery and major degree of placenta previa.

\section{CONCLUSION}

Morbidly Adherent Placenta is almost $100 \%$ associated with previous caesarean by decreasing the $\mathrm{C}$ section rate and early preoperative diagnoses and management of Morbidly Adherent Placenta. We can decrease the morbidity and mortality associated with Morbidly Adherent Placenta.

Copyright@ 15 Dec, 2019.

\section{REFERENCES}

1. Timor-Tritsch, I. E., et al., Cesarean scar pregnancy is a precursor of morbidly adherent placenta. Ultrasound in Obstetrics \& Gynecology, 2014, 44 (3): p.346-353
2. Doumouchtsis, S.K. and S. Arulkumaran, Morbidly adherent placenta. Obstetrics, Gynaecology and Reproductive Medicine, 2010. 20(9): p. 272-277.

3. Narang, L. and E. Chandraharan, Management of morbidly adherent placenta. Obstetrics, Gynaecology and Reproductive Medicine, 2013. 23(7): p. 214-220.

4. Desai, R., Jodha, B. S., and Garg, R., Morbidly adherent placenta and its maternal and fetal outcome. International Journal of Reproduction, Contraception, Obstetrics and Gynecology, 2017, 6 (5), p. 1890-1893.

5. Khirasaria, D. M., and Nayak, T. C., A study of complications in cases of placenta previa. International Journal of Reproduction, Contraception, Obstetrics and Gynecology, 2017, 6 (12), p.5503-5507.

6. Fan, D., et al., Prevalence of placenta previa among deliveries in Mainland China: A PRISMA-compliant systematic review and meta-analysis. Medicine 2016, 95 (40), e5107.

7. Jang, D.G., et al., Maternal outcomes according to placental position in placental previa. International journal of medical sciences, 2011. 8(5): p. 439-444.

8. Rosenberg, T., et al., Critical analysis of risk factors and outcome of placenta previa. Archives of Gynecology and Obstetrics, 2011. 284(1): p. 47-51.

9. Miller, D.A., J.A. Chollet, and T.M. Goodwin, Clinical risk factors for placenta previa-placenta accreta. American Journal of Obstetrics and Gynecology, 1997. 177(1): p. 210-214.

10. Pan, X.-Y., et al., A Marked increase in obstetric hysterectomy for placenta accreta. Chinese medical journal, 2015. 128(16): p. 2189-2193.

11. Aggarwal, R., et al., Morbidly adherent placenta: A critical review. Journal of obstetrics and gynaecology of India, 2012. 62(1): p. 57-61.

12. Kabiri, D., et al., Outcomes of subsequent pregnancies after conservative treatment for placenta accreta. International Journal of Gynecology \& Obstetrics 2014, 127 (2), p.206-210.

13. Chaudhari, H.K., P.K. Shah, and N. D'Souza, Morbidly adherent placenta: Its management and maternal and perinatal outcome. The Journal of Obstetrics and Gynecology of India, 2017. 67(1): p. 42-47.

14. Pinto, P. V., Machado, A. P., and Montenegro, N., Risk of hemorrhage in abnormally invasive placenta according to its management. The Journal of MaternalFetal \& Neonatal Medicine, 2017, 30 (18), p.2139-2145. 


\begin{tabular}{|c|c|c|c|}
\hline \multicolumn{4}{|c|}{ AUTHORSHIP AND CONTRIBUTION DECLARATION } \\
\hline Sr. \# & Author(s) Full Name & Contribution to the paper & Author(s) Signature \\
\hline 1 & Zahra Safdar & & 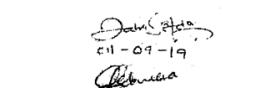 \\
\hline 2 & Sumera Zaib & & s. \\
\hline 3 & Sumera Fatima & 3rd Author & 01104.2019 \\
\hline
\end{tabular}

